\title{
Effects of Backpack Load and Trekking Poles on Energy Expenditure During Field Track Walking
}

\section{(웅 $\odot \ominus$}

\author{
Authors \\ João Paulo Brito', Nuno Garrido², Félix Romero', Adenilson Targino de Araújo Junior³, Victor Machado Reis ${ }^{4}$
}

\section{Affiliations}

1 Sports Sciences School of Rio Maior, Polytechnic Institute of Santarém, Rio Maior, Portugal

2 University of Trás-os-Montes and Alto Douro, Sports, Exercise and Health Department, Vila Real, Portugal

3 Centro de Investigacao em Desporto Saude e Desenvolvimento Humano, Real, Portugal

4 Research Center for Sports, Health \& Human Development, University of Trás-os-Montes \& Alto Douro, Vila Real, Portugal

\section{Key words} energy expenditure, walking, trekking, field track, backpack, poles

$\begin{array}{ll}\text { received } & 07.02 .2017 \\ \text { revised } & 07.04 .2018 \\ \text { accepted } & 18.05 .2018\end{array}$

\section{Bibliography}

DOI https://doi.org/10.1055/a-0637-8719

Sports Medicine International Open 2018; 2: E117-E122

(c) Georg Thieme Verlag KG Stuttgart · New York

ISSN 2367-1890

\author{
Correspondence \\ Prof. Victor Machado Reis \\ Research Center for Sports, Health \& Human Development \\ University of Trás-os-Montes \& Alto Douro \\ Apartado 1013 \\ Vila Real, 5001-801 \\ Portugal \\ Tel.: + 351/259/350 877, Fax: + 351/259/330 168 \\ victormachadoreis@gmail.com
}

\section{ABSTRACT}

This study evaluates the effects of the use of backpack load and trekking poles on field track walking energy expenditure. Twenty male volunteer pole walkers (age: $22.70 \pm 2.89$ years; body mass: $77.90 \pm 11.19 \mathrm{~kg}$; height: $1.77 \pm 0.06 \mathrm{~m}$; percentage of body fat: $14.6 \pm 6.0 \%$ ) walked at a self-selected pace on a pedestrian field track over a period of more than six months. Each subject was examined at random based on four walking conditions: non-poles and non-load, with poles and non-load, nonpoles and with load, with poles and with load. Heart rate, oxygen uptake and energy expenditure were continuously recorded by a portable telemetric system. Non-load walking speed was lower during walking with poles when compared with no poles $(p \leq 0.05)$. Oxygen uptake, energy expenditure and heart rate varied significantly across different conditions. Our results suggest that the use of trekking poles does not influence energy expenditure when walking without an additional load, but it can have an effect during backpack load walking. Moreover, our results indicate that the use of trekking poles may not be helpful to lower the exertion perceived by the subjects when walking with an additional load.

\section{Introduction}

The use of trekking poles is relatively recent among those who pursue competitive walking and mountain walking, but during the last decade poles are used more and more for walking on field tracks $[6,10,16]$. Some of the benefits that have been cited in favor of the use of trekking poles are impact reduction $[4,19]$, walking instability reduction and fatigue reduction while walking with load carriage $[21,28,32]$. However, most of the studies performed until now $[5,17,18,20,34]$ have analyzed walking under laboratory con- ditions and hence lack results that may help in understanding the effects of trekking pole use in load carriage while walking in field conditions.

The first recognized study on load carriage in field conditions [11] showed a great range of physiological responses. Metabolic and physiological responses during walking with load carriage include kinematic, energetic and muscle fatigue changes [13]. Studies done on the treadmill over short periods of time suggest that load carriage leads to an increase energy expenditure (EE) and that 
this increase is related to the extra carried weight, the carried load, the speed and/or to the grade [15, 22, 25]. Additionally, the type of the field track also influences the EE of walking with load carriage [15]. In contrast, some studies either in field conditions [14] or in the laboratory $[25,26]$ suggest that the use of trekking poles with additional load does not lead to changes in EE, although it does reduce the rate of perceived exertion (RPE). Hence, the stabilization conveyed by the use of trekking poles seems to minimize the metabolic effect caused by their use.

Despite some controversy, several studies [6, 16, 26, 29, 31-34] show that the use of trekking poles increases heart rate (HR), oxygen uptake $\left(\mathrm{VO}_{2}\right)$ and EE. Pellegrini et al. [29] report higher total mechanical work in Nordic walking that was mainly due to the greater work required to move the upper limbs and poles. Nordic walking was $20 \%$ less efficient and was metabolically more demanding than walking, and the difference could be ascribed to isometric contraction and low efficiency of the upper limb muscles [30]. The study by Jacobson and Wright [26] reported that although pole use imposed no metabolic consequence, it did evoke a greater heart rate (113.5 vs. $107 \mathrm{bpm}$ ), and subjects backpacked more comfortably as indicated by their ratings of perceived exertion (10.8 vs. 11.6). The increased cardiovascular demand was likely to support the greater muscular activity in the upper extremities, as was observed in the triceps brachii. In contrast, some studies $[32,34]$ report increments in the subject's EE when using trekking poles during walking. Porcari et al. [31] and Saunders et al [32] suggest that the increase of $\mathrm{HR}, \mathrm{VO}_{2}$ and $\mathrm{EE}$ with the use of trekking poles is due to additional involvement of upper body muscle groups. It is possible that the use of trekking poles with an exaggerated arm swing may have induced the rise in EE rather than the use of poles.

Some have reported that the use of trekking poles enabled subjects to walk at a faster speed as well as with an increased stride length $[10,19,35]$. Others failed to show these biomechanical benefits of pole walking $[14,18,19]$. Jacobson et al. [25] indicated that pole use while walking on a treadmill at a positive slope did not cause significant increases in $\mathrm{HR}, \mathrm{VO}_{2}$ or $\mathrm{EE}$. These results were partially confirmed by others, although the HR was significantly higher in the non-pole exercise condition [14]. However, studies done on a field track at a self-selected speed showed that the use of trekking poles during walking increased $\mathrm{EE}, \mathrm{VO}_{2}$ and $\mathrm{HR}[6,10,16]$.

The use of trekking poles can increase the $E E$ at a given walking speed without increasing RPE [10, 25, 32]. Moreover, some reported a reduction in $\mathrm{RPE}$ when walking with trekking poles $[21,24,14,16]$ and with load carriage $[10,25,31]$. The use of trekking poles in walking with load carriage seems to cause a distribution of forces that ease stride and decrease discomfort due to the backpack load [3, 6, 25, 26].

Despite the idea that there is an increase in stability and balance caused by trekking poles when walking on treadmill [10, 19], there are few studies on the effects of their use under field conditions. To the best of our knowledge, the interaction between load carriage and use of poles in terrain walking at a self-selected pace is not evident in the literature. Thus, the present study aimed to investigate the effects of the use of trekking poles and/or load carriage in EE and RPE in novice/beginner pole walkers walking on field tracks.

\section{Materials and Methods}

\section{Participants}

Twenty Caucasian males (mean \pm SD: age $22.70 \pm 2.89$ years; body mass $77.90 \pm 11.19 \mathrm{~kg}$; height $1.77 \pm 0.06 \mathrm{~m}$; estimated fat mass $14.59 \pm 5.99 \%$; rest oxygen consumption $3.27 \pm 0.46 \mathrm{ml} . \mathrm{kg}^{-1}$. $\mathrm{min}^{-1}$ ) with at least 6 months of previous practice volunteered for this cross-sectional study. The sample dimension analysis was performed using $G$ * Power 3.1 software [14]. Under a framework assuming an estimation error of $\alpha=0.05$, power $=80 \%, E S=0.25$, having 2 measures (loads) $\times 2$ conditions of exercise, an $n$ of 18 was necessary to reach a statistical power of $80.4 \%$. Therefore, 20 subjects were assigned to each exercise.

Subjects filled out a health history questionnaire and signed a consent form. Subjects were instructed on the use of trekking poles and backpack load and all were apparently healthy and physically active. The present study meets the ethical standards of the International Journal of Sports Medicine [19].

\section{Experimental design}

This was a cross-sectional study.

During the first session, measurements of body mass and height were taken using a stadiometer (SECA, Germany, Hamburg) and bio-impedance measurements were also taken (Omron BF300, Omron, Matsusaka Co. LTD., Japan).

On separate days, subjects started the four exercise conditions on a field track with a distance and height above sea level of 821 meters and 65 meters, respectively. The field track was a forest trail on firm ground and without obstacles. The tests were done during the morning at a temperature of $20^{\circ} \mathrm{C}$ to $22^{\circ} \mathrm{C}$ and a humidity of 50 to $60 \%$. The trail segment was selected for grade variability lower than $1 \%$ over the entire distance of the segment. For that purpose, an altimetry survey was performed with a Sokkia $130 \mathrm{R}$ (Sokkia, Casagiove, Italy).

The subjects performed the four exercise conditions (on different days separated by at least twenty-four hours) in a randomized order: walk without trekking poles or load (W); walk without trekking poles but with additional load $\left(\mathrm{W}_{\mathrm{L}}\right)$; walk with trekking poles and no load $\left(W_{\mathrm{P}}\right)$; walk with trekking poles and additional load $\left(W_{\mathrm{PL}}\right)$. Walking speed was self-selected as suggested in the literature [32]. The self-selection of speed affords the subjects the most benefit from the use of trekking poles [14, 25].

Before and during the walking sessions, the wind speed was measured with a Skywatch Xplorer 3 anemometer (JDC Electronic, Yverddon-les-Bains, Switzerland). Exercise trials done at a wind speed below $15 \mathrm{~km} \cdot \mathrm{h}^{-1}$ were accepted because this is the speed up to which aerodynamic resistance is considered negligible [9]. Whenever the wind speed exceeded that value, the test was stopped and repeated twenty-four hours later.

The energy expenditure (EE) during the trials was calculated from the measurement of $\mathrm{VO}_{2}$ using a $\mathrm{K}_{4} \mathrm{~b}^{2}$ gas analyzer (Cosmed, Rome, Italy) and based on the fraction of oxygen and carbon dioxide in expired air $\left(\mathrm{FEO}_{2}\right.$ and $\left.\mathrm{FECO}_{2}\right)$, [12]. The HR was continuously measured using a wireless HR monitor (Polar, Kempele, Finland) linked to $\mathrm{K}_{4} \mathrm{~b}^{2}$. The $\mathrm{VO}_{2}$ was recorded every 20 s and then averaged per minute. The maximum difference allowed between two con- 
secutive minutes to assure stabilization in $\mathrm{VO}_{2}$ was $2.1 \mathrm{ml} . \mathrm{kg}^{-1}$. $\mathrm{min}^{-1}$. Gas exchange variables were averaged during the last $2 \mathrm{~min}$ of each trial after metabolic steady state achievement. The gas analyzer was calibrated before each test as instructed by the manufacturer (gas calibration, turbine calibration, delay calibration and room air calibration). At the end of each trial the subjects were asked to assess their perceived rate of exertion with the modified Borg's scale (CR-10).

The gross cost of transport (CoT) was calculated by measuring total exercise oxygen uptake and by converting the energy equivalent into joules $(1 \mathrm{~L} \mathrm{O} 2=21 \mathrm{KJ})$. The cost of transport was expressed relative to body mass and was divided by distance travelled.

Trekking poles weighing $510 \mathrm{~g}$ each (Makalu ultralite titanium, Leki, Buffalo, NY, USA) were individually fit for each subject with adjustable telescopic sections from $69 \mathrm{~cm}$ to $133 \mathrm{~cm}$ in height. The height of the trekking poles was adjusted individually, keeping the subject in the upright biped position, with the arm next to the body and the elbow at an angle of $90^{\circ}[19,26]$. The single instruction that the subjects received about using trekking poles was that each pole should be used in a position opposite to the counter-side lower $\operatorname{limb}[19]$.

The load that was carried out corresponded to $25 \%$ of the body mass $(19.42 \pm 2.84 \mathrm{~kg})$. The selected load percentage is similar to the load that subjects usually carry when trekking for more than one day [8]. The chosen backpack, the Sherpa 60+10 L (Vango, Glasgow, Scotland) is equipped with an inside frame and adjustable shoulders and sternum straps, hip belt, and load lifters. These features are in agreement with what is suggested elsewhere [27]. The load was distributed in a similar way using the pockets of the backpack to avoid lack of balance and to keep the center of mass in a similar position to the natural load that is usually used in trekking (multi-day walks), that is, in the middle section of the backpack.

\section{Statistics}

Data are presented as means, standard deviations (SD), maximum, minimum, means difference (MD) and $95 \%$ confidence intervals of MD. Differences between exercise conditions were tested by ANOVA [2 (hiking poles) x 2 (load carriage)] followed by the posthoc Bonferroni test. The sphericity assumption was verified by Mauchly's test. Significance level was set at $p \leq 0.05$. Data was processed with SPSS 14.0 (SPSS Science, Chicago, USA). Research data were made public on Figshare at https://figshare. com/s/55afa5cc918140866d6d.

\section{Results}

All subjects' $\mathrm{VO}_{2}$ attained a steady state within the first three minutes of exercise during the different exercise conditions ( $>$ Fig. 1). $>$ Table 1 presents a descriptive analysis of the variables that were assessed and $>$ Table 2 presents the comparisons that were evaluated.

Several significant differences in $\mathrm{VO}_{2}$, CoT and $\mathrm{HR}$ were observed between the different exercise conditions. Exceptions were verified for $\mathrm{VO}_{2}$ and $\mathrm{CoT}$ in the $\mathrm{W}$ vs. $\mathrm{W}_{\mathrm{P}}$ comparison and for $\mathrm{HR}$ in the $\mathrm{W}_{\mathrm{L}}$ vs. $W_{L P}$ comparison. The RPE was not affected by the use of poles but was altered when load carriage was present. The use of poles reduced the walking speed without extra load.

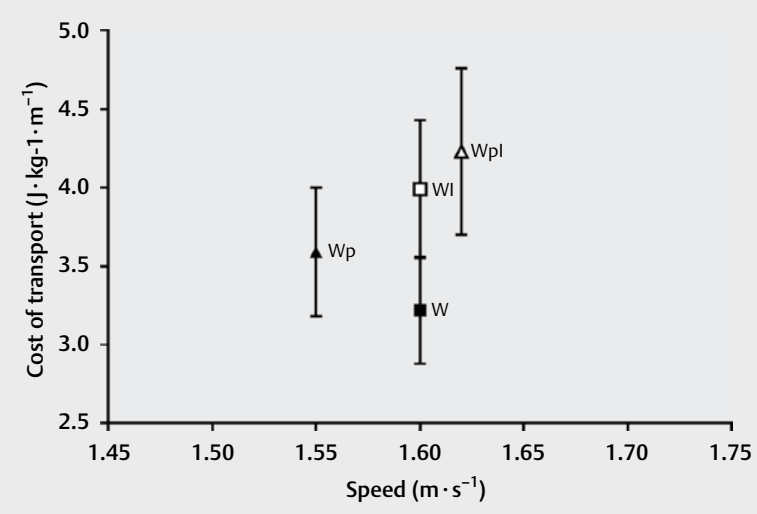

- Fig. 1 Oxygen uptake profile of a subject walking at the four exercise conditions: $W=$ walking without trekking poles and without load; $W_{P}=$ walking with trekking poles but without load; $W_{L}=$ walking without trekking poles but with load; $\mathrm{W}_{\mathrm{PL}}=$ walking with trekking poles and with load.

The interaction of pole use and load carriage presented a significant effect on the metabolic cost $\left(F=2563.19 ; \mu^{2}=0.993\right.$; $\mathrm{p}<0.000)$.

\section{Discussion}

The present study investigated the effects of the use of trekking poles and/or load carriage in EE and RPE while walking on field tracks. Significant differences in HR and walking speed were found $(p \leq 0.05)$ in the comparisons between walking with vs. without poles. Moreover, the use of poles significantly increased EE (as expressed by $\mathrm{VO}_{2}$ ) and CoT ( $\left.\mathrm{C} \leq 0.01\right)$, whereas no differences were observed in HR, RPE and walking speed between walking with or without poles when carrying a backpack load.

\section{Walking with a backpack load}

In the present study, walking speed did not vary with the backpack load. This fact may be justified by the fact that the speed at which walking efficiency is maximum is the same with or without load primarily due to the pendular mechanism $[2,15,16]$. Additionally, the biomechanical factors of walking may not change significantly with load [7]. Some [1, 2] state that while walking long distances at speeds that are economically comfortable (self-selected), the loads around $1 / 4$ of body mass seem appropriate. Therefore, the results of the present study do support those statements.

It has also been suggested that load carriage influences $\mathrm{EE}$, but it does not influence the optimum walking speed [13]. Our study supports such an assumption, because we have observed a significant increase in EE without changes in speed. Others agree that subjects hardly ever choose ideal economical speeds [2].

Our results make evident the effects of carrying an additional load, as demonstrated by a significant increase in $\mathrm{VO}_{2}$, CoT, HR and RPE, which confirms previous results [1,2,22]. However, in the present study, with an addition of $25 \%$ of body weight, changes on $\mathrm{VO}_{2}, \mathrm{HR}$ and RPE were smaller than those verified during treadmill walking [3]. It is possible that the unusual motor pattern of walk- 

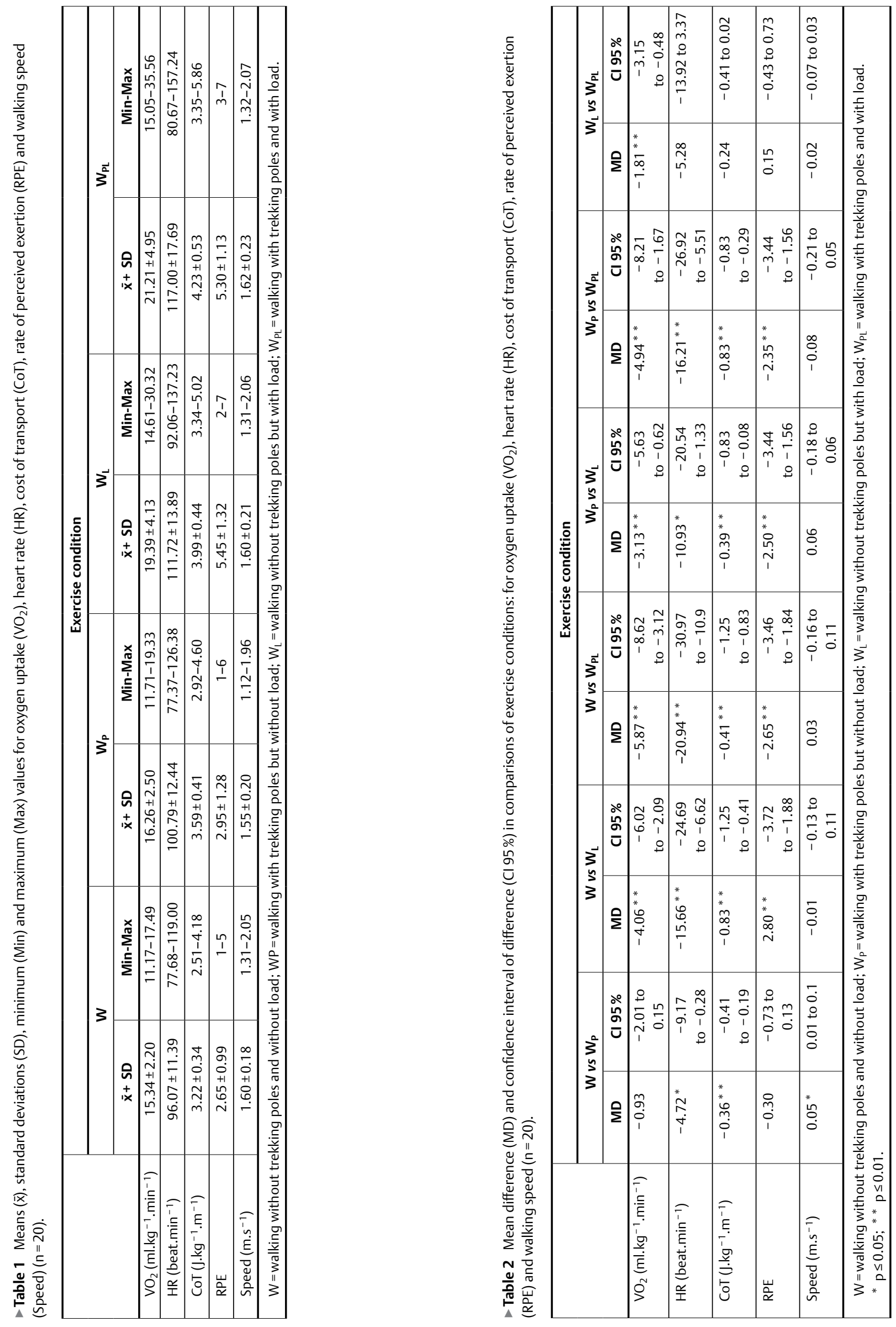
ing on the treadmill can explain discrepancies between treadmill and field data.

\section{Walking with trekking poles}

Some studies refer to an increase in walking speed with the use of trekking poles [19, 26, 31]. Others have previously described similar walking speeds with and without poles [6]. On the contrary, in the present study we verified a decrease in speed when poles were used without additional load. The inexperience of the subjects could have contributed to the decrease of the speed with the use of trekking poles [23].

In the present study, the use of trekking poles during walking did not cause changes in $\mathrm{VO}_{2}$ and in $\mathrm{EE}$. These results confirm previous data $[14,21,25]$. The fact that $E E$ has not presented significant differences could be explained by a possible increase in walking efficiency provided by the use of poles [28]. In contrast, Porcari et al. [31] Sklar et al [34] and Church et al. [6] report increases in $\mathrm{VO}_{2}$, EE and $\mathrm{HR}$ when comparing non-pole with pole walking. Although the results herein showed that poles did not significantly influence $\mathrm{VO} 2$ and $\mathrm{EE}$, when $\mathrm{EE}$ was expressed normalized to body mass and distance, there were significant differences.

It is possible that the use of trekking poles with a large amplitude of arm movements may induce increases in EE [31] despite this is more likely to occur at low speeds $\left(<1.4 \mathrm{~m} . \mathrm{s}^{-1}\right)$. The self-selected speeds of our subjects on level ground when using trekking poles were lower than those in the aforementioned studies. Moreover, Jacobson et al. [23] observed that the use of trekking poles at a grade of $0 \%$ did not cause a transfer of forces from the lower to upper limbs, a fact that could also justify the lack of change of CoT that we observed. Therefore, if the use of trekking poles is performed without large amplitude of arm movements, it will eventually influence solely the HR, as verified in the present study. Controversial results regarding the EE changes with the use of poles may be explained by differences in the exercise protocols among studies.

In the present study, RPE showed no significant differences between $W$ and $W_{\text {p. }}$ Others previously reported no differences in RPE comparing walking with and without poles [6, 15, 34]. However, our results are at odds with those that observed a decrease in RPE with the use of trekking poles [10, 24, 31]. Most of the studies that report a decrease in RPE with the use of poles were performed in the laboratory $[25,26,31]$. Therefore, we may conclude that the effect of using trekking poles on RPE seems more likely to occur on the treadmill.

\section{Walking with backpack load and with trekking poles}

In this study, we verified that the use of trekking poles did not induce significant changes in speed, although there was a trend to increase average speed when using a backpack load. It was suggested that trekking poles allow subjects to have better walking posture and mechanical efficiency when walking with an additional load, thereby reducing the CoT $[19,26]$.

Although the load carriage increased $\mathrm{VO}_{2}$ and $\mathrm{EE}\left(\mathrm{J} \cdot \mathrm{min}^{-1}\right)$, there were no significant differences between trials (with vs. without trekking poles) during load carriage when data was normalized to body weight and distance $\left(\mathrm{CoT}=\mathrm{J} \cdot \mathrm{kg}^{-1} \cdot \mathrm{m}^{-1}\right)$. The current normalized data suggest that when the poles are used without excessive move- ments during load carriage, no additional energy expenditure occurs on level ground despite the added weight of the poles.

Wenos et al. [14] did not find significant differences in EE with or without poles. However, a higher HR was described in that same study for the pole walking condition. In contrast, the results in the present study indicate a higher EE with the use of poles during backpack load walking (MD -0.24; Cl $95 \%-0.41$ to 0.02 ), though with no differences in HR. The interaction between the load carriage and the use of trekking poles during the stance phase and the swing phase can also influence walking between subjects.

The values of RPE that were registered in the present study with or without poles during backpack walking presented no differences. In contrast, others have concluded that the use of trekking poles when walking with additional load was able to cause a decrease in RPE $[21,24]$. Jacobson et al. [25] state that the decrease in RPE is due to better stability provided by trekking poles and that the decrease is more evident on ground with a positive grade. Therefore, the positive effect of pole use on RPE could be explained by subjects' descriptions of greater comfort while carrying an additional load [19,25]. Finally, the unexpected result in the CoT with and without poles and load carriage deserves further studies.

In conclusion, the present study extends the precedent literature on energy expenditure and rate of perceived exertion while walking in a field track in different exercise conditions (with or without backpack and with or without trekking poles). Our results suggest that the use of trekking poles does not influence energy expenditure when walking without an additional load, but it can have an effect during backpack load walking. Moreover, our results indicate that the use of trekking poles may not be helpful to lower the exertion perceived by novice Nordic walkers when walking with an additional load.

\section{Conflicts of Interest}

The authors declare that they have no conflict of interest.

\section{References}

[1] Abe D, Yanagawa K, Niihata S. Effects of load carriage, load position, and walking speed on energy cost of walking. Appl Ergon 2004; 35: 329-335

[2] Bastien G], Willems PA, Schepens B, Heglund NC. Effect of load and speed on the energetic cost of human walking. Eur J Appl Physiol 2005; 9: 76-83

[3] Bhambhani Y, Maikala R. Gender differences during treadmill walking with graded loads: Biomechanical and physiological comparisons. Eur J Appl Physiol 2000; 81: 75-83

[4] Bohne M, Abendroth-Smith ]. Effects of hiking downhill using trekking poles while carrying external loads. Med Sci Sports Exerc 2007; 39: 77-183

[5] Carey TS, Crompton RH. The metabolic costs of bent-hip, bent-knee walking in humans. J Hum Evol 2005; 48: 25-44

[6] Church TS, Earnest CP, Morss GM. Field-testing of physiological responses associated with Nordic walking. Res Q Exerc Sport 2002; 73 : 296-300 
[7] Dames KD, Smith JD. Effects of load carriage and footwear on spatiotemporal parameters, kinematics and metabolic cost of walking. Gait \& Posture 2015; 42: 122-126

[8] DeVoe D. Caloric expenditure during backpacking. J Hum Mov Stud 2001; 40: 259-268

[9] Di Prampero PE. The energy cost of human locomotion on land and in water. Int J Sports Med 1986; 7: 55-72

[10] Doshi G, Shende M, Bhalerao S, Patel H, Wakpaijan K, Thaker Z, Rao T. Effects of Nordic walking on gait parameters on leveled ground $\left(0^{\circ}\right)$ and inclined slope $\left(30^{\circ}\right)$ in healthy individuals. 2017 ; 4: 56-61

[11] Durnin JVGA. The oxygen consumption, energy expenditure and efficiency of climbing with loads at low altitudes. J Physiol 1955; 128: 294-309

[12] Elia M, Livesey G. Energy expenditure and fuel selection in biological systems: The theory and practice of calculations based on indirect calorimetry and tracer methods. World Rev Nutr Diet 1992; 70: 68-131

[13] Falola JM, Delpech N, Brisswalter J. Optimization characteristics of walking with and without a load on the trunk of the body. Percept Motor Skill 2000; 91: 261-272

[14] Faul F, Erdfelder E, Lang AG, Buchner AG. * Power 3: A flexible statistical power analysis program for the social, behavioral, and biomedical sciences. Behav Res Methods 2007; 392: 175-191

[15] Gomeñuka N, Bona R, Rosa R, Peyré-Tartaruga L. The pendular mechanism does not determine the optimal speed of loaded walking on gradients. Hum Mov Sci 2016; 47: 175-185

[16] Gomeñuka A, Bona L, Rosa R, Peyré-Tartaruga L. Adaptations to changing speed, load, and gradient in human walking: Cost of transport, optimal speed, and pendulum. Scand J Med Sci Sports 2014; 24: 165-173

[17] Gottschall J, Kram R. Energy cost and muscular activity required for propulsion during walking. J Appl Physiol 2003; 94: 1766-1772

[18] Hansen L, Henriksen M, Larsen P, Alkjaer T. Nordic walking does not reduce the loading of the knee joint. Scand J Med Sci Sports 2008; 18 436-441

[19] Harriss D], Macsween A, Atkinson G. Standards for ethics in sport and exercise science research: 2018 update. Int J Sports Med 2017; 38: $1126-1131$

[20] Hoffman MD, Millet GY, Candau RB, Rouillon JD. Evaluation of a theoretical model to quantify the sources of metabolic cost in walking. Am J Phys Med Rehab 2004; 83: 353-362

[21] Howatson G, Hough P, Pattison J, Hill JA, Blagrove R, Glaister M, Thompson KJ. Trekking poles reduce exercised-induced muscle injury during mountain walking. Med Sci Sports Exerc 2011; 43: 140-145
[22] Huang TP, Kuo AD. Mechanics and energetics of load carriage during human walking. J Exp Biol 2014; 217: 605-613

[23] Jacobson BH, Kaloupek J, Smith DB. Load carriage force production comparison between standard and anti-shock trekking poles. Sport J 2005 [cited 2017 Feb 06]. Available from http://thesportjournal.org/ article/load-carriage-force-production-comparison-between-standardand-anti-shock-trekking-poles/

[24] Jacobson B, Wright T. A field test comparison of hiking stick use on heart rate rating of perceived exertion. Percept Motor Skill 2000; 87: 435-438

[25] Jacobson BH, Wright T, Dugan B. Load carriage energy expenditure with and without hiking poles during inclined walking. Int J Sports Med 2000; 21: 356-359

[26] Knight C, Caldwell G. Muscular and metabolic cost of uphill backpacking: Are hiking poles beneficial? Med Sci Sports Exerc 2000; 32: 2093-2101

[27] Murtagh EM, Boreham CA, Murphy MH. Speed and exercise intensity of recreational walkers. Prev Med 2002; 54: 397-400

[28] O'Dwyer N], Neilson PD. Metabolic energy expenditure and accuracy in movement. In: Sparrow WA. ed. Energetics of Human Activity. Champaign, IL: Human Kinetics; 2000: 1-42

[29] Pellegrini B, Peyre-Tartaruga L, Zoppirolli C, Bortolan L, Bacchi E, Figard-Fabre H, Schena F. Exploring muscle activation during Nordic walking: A comparison between conventional and uphill walking. Plos One 2015; 10: 1-13

[30] Pellegrini B, Peyre-Tartaruga L, Zoppirolli C, Bortolan L, Savoldelli A, Minetti A, Schena F. Mechanical energy patterns in Nordic walking: Comparisons with conventional walking. Gait Posture 2017; 51: 234-238

[31] Porcari J, Hendrickson T, Walter P, Terry L, Walsko G. The physiological responses to walking with and without power poles TM on treadmill exercise. Res Q Exerc Sport 1997; 6: 161-166

[32] Saunders M], Hipp GR, Wenos DL, Deaton ML. Trekking poles increase physiological responses to hiking without increased perceived exertion. J Strength Cond Res 2008; 22: 1468-1474

[33] Schiffer T, Knicker A, Montanarella M, Struder H. Mechanical and physiological effects of varying pole weights during Nordic walking compared to walking. Eur J Appl Physiol 2011; 111: 1121-1126

[34] Sklar J, DeVoe D, Gotshall R. Metabolic effects of using bilateral trekking poles whilst hiking. J Hum Mov Stud 2003; 44: 73-185

[35] Willson J, Torry MR, Decker M], Kernozek T. Effects of walking poles on lower extremity gait mechanics. Med Sci Sports Exerc 2001; 33: $142-147$ 